Research Article

\title{
Artificial Ground Motions and Nonlinear Response of RC Structures
}

\author{
Marco Filippo Ferrotto $\left(\mathbb{D},{ }^{1}\right.$ Francesco Basone, ${ }^{2}$ Panangiotis G. Asteris $\left(\mathbb{D},{ }^{3}\right.$ \\ and Liborio Cavaleri (iD) \\ ${ }^{1}$ Department of Engineering, University of Palermo, Viale delle Scienze, Palermo, Italy \\ ${ }^{2}$ University of Enna "Kore", Enna, Italy \\ ${ }^{3}$ School of Pedagogical \& Technological Education, Athens, Greece
}

Correspondence should be addressed to Liborio Cavaleri; liborio.cavaleri@unipa.it

Received 11 June 2020; Revised 8 August 2020; Accepted 17 August 2020; Published 30 August 2020

Academic Editor: Filippo Ubertini

Copyright ( 92020 Marco Filippo Ferrotto et al. This is an open access article distributed under the Creative Commons Attribution License, which permits unrestricted use, distribution, and reproduction in any medium, provided the original work is properly cited.

\begin{abstract}
The selection of seismic inputs for nonlinear dynamic analysis is widely debated, mainly focusing on the advantages and disadvantages provided by the choice of natural, simulated, or artificial records. This work proves the differences in the structural behavior of RC buildings when using accelerograms with different levels of stationarity. Initially, nonlinear response under three sets of accelerograms equivalent in terms of pseudo acceleration spectrum is evaluated and compared. Then, the results of incremental dynamic analyses are compared by the statistical point of view considering different levels of irregularity for the reference structure.
\end{abstract}

\section{Introduction}

The step-by-step dynamic analysis requests accelerograms that, in agreement to the actual codes (i.e., EC8, Italian code, etc.), may be (1) recorded during a real earthquake, (2) generated through a physical simulation of source and travel path mechanisms, or (3) artificial that is generated so as to match an elastic target response spectrum. In the first two cases, each sample has to be adequately qualified with regard to the seismogenetic features of the sources and the soil conditions appropriate to the site, and their values have to be scaled to the value of the peak ground acceleration (PGA) for the zone under consideration. In the third case, an appropriate generation technique has to be chosen able to match, besides the target elastic response spectrum, some characteristics requested by actual codes. For example, Eurocode 8 [1] suggests that the minimum duration of the stationary part should be 10 seconds without giving suggestions about the previous and the following parts. Italian code that does not call "stationary" the middle part of an accelerogram but "pseudo stationary" suggests that the pseudo stationary part itself has to be preceded by a signal increasing from zero and has to be followed by a signal decreasing up to zero without giving any details about the stationarity in frequency. EC8 and Italian code are a proof that the generation of accelerograms is not always based on the same suggestions and that well defined procedures for the generation of artificial ground motions are not provided in general by technical codes. On the other hand, the research on the dynamic of RC structures gains more and more interest in the last period and a number of studies have been aimed at investigating the seismic response of classic and nonconventional structures [2-6].

To this point, the question is how two accelerograms nominally equivalent but different in terms of stationarity may affect the structural response? This question is much more important considering that various strategies of generation of spectrum compatible accelerograms filtered by samples of stationary random processes are available in the literature [7-9] and considering that the simplified assumption of stationarity is a strong idealization of the ground accelerations. In fact, accelerograms are really 
characterized by a variation in amplitude and frequency content. In other words, the approaches usually proposed for the input modelling (e.g., [10-12]) require caution and a verification of reliability.

However, the consciousness of the real nature of an earthquake has made some generation of spectrum compatible nonstationary earthquakes strategies be formulated [13-15] although these are not still suggested by technical codes.

In order to know if the use of nonstationary input would be basic or if it would be only a further complication in the seismic assessment of structures, the paper investigates the influence of the nonstationary seismic signals on the nonlinear response of RC structures, comparing the demand and the seismic damage with the case of stationary input. First, three sets of artificial accelerograms are generated, that are stationary, nonstationary evenly modulated, and fully nonstationary. Earthquake response parameters, such as interstorey drifts and floor torsion angles of buildings having a different degree of structural regularity, are monitored by standard nonlinear dynamic analyses. Then, Incremental Dynamic Analysis curves obtained for each set of artificial accelerograms are compared in order to evaluate the degree of dependence from the typology of signal and to prove if/how much the nonlinear analysis that is actually widely suggested [16-20] is sensible to the type of input.

\section{Input Generation}

The three sets of accelerograms aforementioned (50 stationary, 50 nonstationary evenly modulated, and 50 fully nonstationary) were generated by using the procedure proposed by Shinozuka and Sato [21]. For the case of stationary signals (S), no further manipulations needed, while to obtain nonstationary evenly distributed and fully nonstationary signals, appropriate modulating functions were reported in agreement to the strategy suggested by Cacciola [13]. In detail, the $i^{\text {th }}$ spectrum compatible stationary accelerogram $\ddot{u}_{\mathrm{i} . \mathrm{g}}^{\mathrm{ST}}$ was obtained as follows:

$$
\ddot{u}_{\mathrm{i} . \mathrm{g}}^{\mathrm{ST}}(t)=\sum_{r=1}^{m_{c}} \sqrt{2 G_{\ddot{U}_{\mathrm{g}}}}(r \Delta \omega) \cdot \Delta \omega \cdot \sin \left(r \Delta \omega \mathrm{t}+\theta_{r}^{(i)}\right), \quad 0<t<\bar{t},
$$

where $\theta_{r}^{(i)}$ is the random phase, $\Delta \omega$ is the frequency step, $m_{\mathrm{c}}$ is the number of harmonics that constitute the signal (obtained as $\left[\omega_{f}-\omega_{i}\right] / \Delta \omega$ with $\omega_{i}$ and $\omega_{f}$ cutoff frequencies), $G_{\ddot{U}_{g}}(\cdot)$ is the spectrum compatible power spectral density function defined in the range $\left[\omega_{i} / \omega_{f}\right]$, and finally $\bar{t}$ is the signal duration correlated to the cutoff frequency $\omega_{i}$ by the equation $\bar{t}=2 \pi / \omega_{i}$.

Equation (1) gives zero-mean stationary Gaussian random processes, fully defined by the spectrum compatible power spectral density function $G_{\ddot{U}}(\cdot)$ whose complete expression can be found in Cacciola [13].

Evenly modulated nonstationary seismic signals (NSEM), characterized by a variation of the peak levels varying the time, were obtained by scaling the ordinates of stationary inputs generated as before discussed through the modulating function proposed by Hsu and Bernard [22], that is,

$$
\varphi(t)=\varepsilon \mathrm{t} \exp (-\mu \mathrm{t})
$$

where $\varepsilon=\mu \exp (1) \sec ^{-1}$ and $\mu=1 / 5 \sec ^{-1}$.

Fully nonstationary accelerograms (FNS) were obtained using the following modulating function proposed by Spanos and Salomons [23]:

$$
\varphi(\omega, t)=\varepsilon(\omega) t \exp (-\mu(\omega) t),
$$

where $\varepsilon(\omega)$ and $\mu(\omega)$ are defined as

$$
\begin{aligned}
& \mu(\omega)=\frac{1}{2} 0.15+\left(\frac{\omega^{2}}{225 \pi^{2}}\right)\left[\sec ^{-1}\right], \\
& \varepsilon(\omega)=\frac{\omega \sqrt{2}}{15 \pi}\left[\sec ^{-1}\right] .
\end{aligned}
$$

Of each generated signal the spectrum was calculated; then, the average of the spectra of each of the three types of accelerograms was compared with the target spectrum whose characterizing parameters are inserted in Table 1. In Figure 1, the above comparison is shown.

In Figure 2, the different characteristics of three samples belonging to the three sets of accelerograms can be observed. The stationary signal (a) shows regularity in the peaks and in the distance between the peaks. The nonstationary evenly modulated signal (b) shows a variation in the peaks at the end and at the back end but shows regularity in the distance between the peaks. The fully nonstationary signal (c) shows a variation in the peaks and the distance between the peaks from the back end to the end.

\section{Reference Structural Models}

3.1. Geometry and Main Futures of the Models. Four different typologies of reinforced concrete 3D structures, named M1, $\mathrm{M} 2, \mathrm{M} 3$, and M4, were considered for the following comparisons. Such structures (a) have the same interstorey height of $3 \mathrm{~m}$ and (b) are in plan inscribable in a rectangle having dimensions of $12.1 \mathrm{~m} \times 8.1 \mathrm{~m}$ and interaxis between the frames of $5.50 \mathrm{~m}-5.50 \mathrm{~m}-2.70 \mathrm{~m}$ along $y$-direction and $4.30 \mathrm{~m}-3.00 \mathrm{~m}-4.80 \mathrm{~m}$ along $x$-direction. Different geometries in plan and elevation were defined in each model (simply by removing some members in the M1 model) in order to have different dynamics properties. In detail, M1 model had the same regular plan at each floor; M2 model had L-shape with the same plan at each floor; M3 model had L-shape with equal plan at the first two floors and rectangular plan at the top floor along $x$-direction; M4 had C-shape and plan reducing from the base to the top. The models were designed according to the actual [24] requirements in the case of seismic design for new constructions. The structures were modelled by the SeismoStruct software platform [25]. Distributed plasticity fiber-section elements were used for RC members. 
TABLE 1: Target spectrum parameters.

\begin{tabular}{lcccccrr}
\hline$T_{\mathrm{B}}$ & $T_{\mathrm{C}}$ & $T_{\mathrm{D}}$ & $S_{\mathrm{e}}\left(T_{\mathrm{B}}\right)$ & $S_{\mathrm{e}}\left(T_{\mathrm{C}}\right)$ & $S_{\mathrm{e}}\left(T_{\mathrm{D}}\right)$ & ag \\
& $\mathrm{sec}$ & & $\mathrm{g}$ & $F_{0}$ \\
\hline 0.120 & 0.361 & 2.566 & 0.582 & 0.582 & 0.082 & 0.241 & 2.411 \\
\hline
\end{tabular}

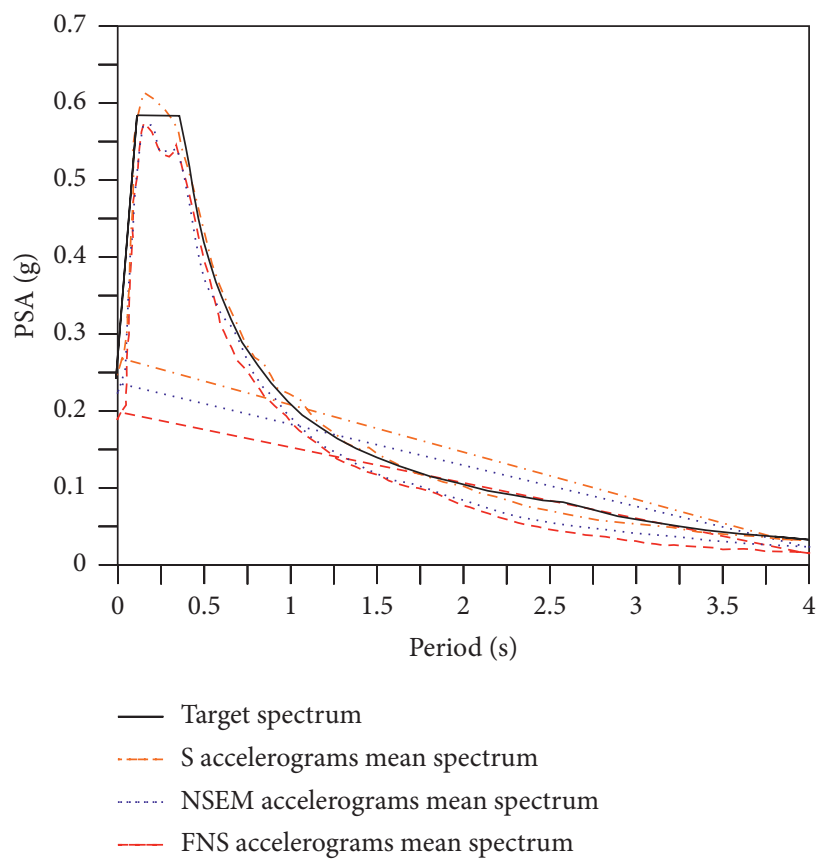

Figure 1: Target spectrum and mean spectra obtained from the 3 sets of seismic inputs.

An overall view of the reference structures is shown in Figure 3, and some design details are described in Table 2.

3.2. Materials. Two different stress-strain laws were attributed to the (concrete) fibers constituting the core and the cover of the cross sections as suggested generally in the literature (e.g., [26]. For the concrete of the cover (unconfined), the compressive strength $f_{\mathrm{c} 0}=25 \mathrm{MPa}$, reached at the peak strain $\varepsilon_{\mathrm{c} 0}=0.0020$, was considered. The postpeak branch was characterized by a decreasing strength up to the ultimate strain $\varepsilon_{\mathrm{cu}}$ of 0.0035 . For the core, the model by Mander et al. [27], characterized by a peak stress $f_{\text {cco }}=33 \mathrm{MPa}$, strain at the peak stress $\varepsilon_{\mathrm{cco}}=0.0033$, and ultimate strain $\varepsilon_{\mathrm{ccu}}=0.0080$, was considered. As regards the steel rebars, an elastoplastic law having yielding stress $f_{\mathrm{ys}}=450 \mathrm{MPa}$ with a hardening up to $540 \mathrm{MPa}$ associated with an ultimate strain of $0.8 \%$ was fixed. The model for the steel of the rebars was characterized by the same stiffness at each cycle while the models for the concrete were characterized by a reduction of stiffness at each cycle. In each case, the collapse of an RC member was associated with the ultimate strain of the concrete of the core, producing only a reduction of the cross section because of reaching the ultimate strain in the cover. Figure 4 shows the constitutive laws obtained for the materials with the mechanical characteristics mentioned above and used for the numerical analyses.

\section{Nonlinear Behavior of the Reference Structures Obtained with Standard Time- History Analyses}

Nonlinear responses of the four reference models under the 3 sets of seismic signals were evaluated considering the interstorey drifts at each floor and the interstorey relative torsion angles for each floor.

In Figure 5, the responses in terms of displacement of the first floor of the model 1 are shown evidencing that the effect of the stationarity and nonstationarity of the input is not more clearly recognizable like in the input signals.

For an overall frame of the responses, the average values of the interstorey drifts and the relative torsion angles are shown in Figure 6, obtained for the different structural models and each floor. As it can be seen, stationary inputs cause amplified structural responses with respect to nonstationary inputs in terms of both interstorey drifts and interstorey relative torsion angles.

Figure 7 shows the variation ratios of the average nonstationary seismic demands compared with the stationary case. By this figure, it is much clearer that stationary inputs always cause the highest values for both cinematic data considered.

Furthermore, it can be observed that, in general, for the cases studied, stationary signals cause a more conservative 


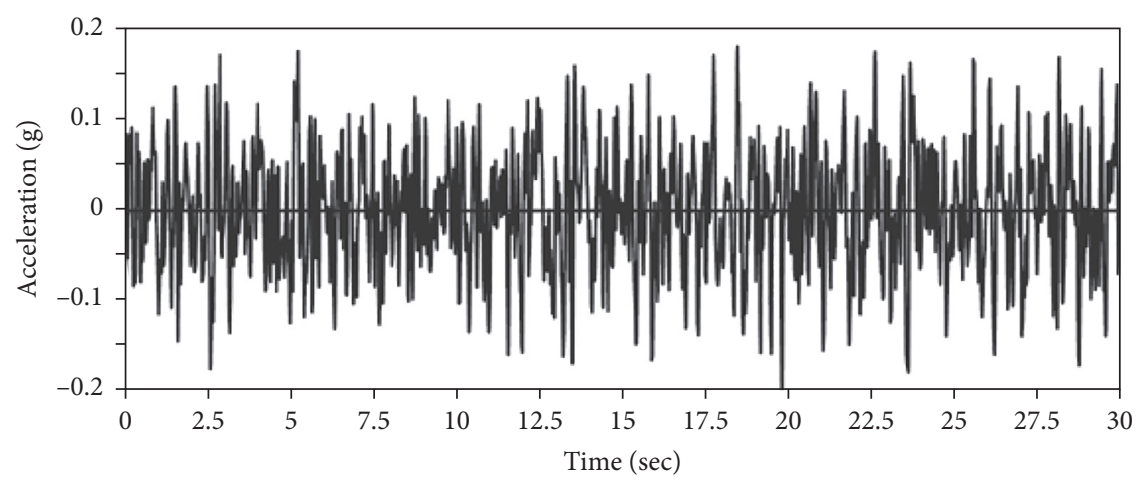

(a)

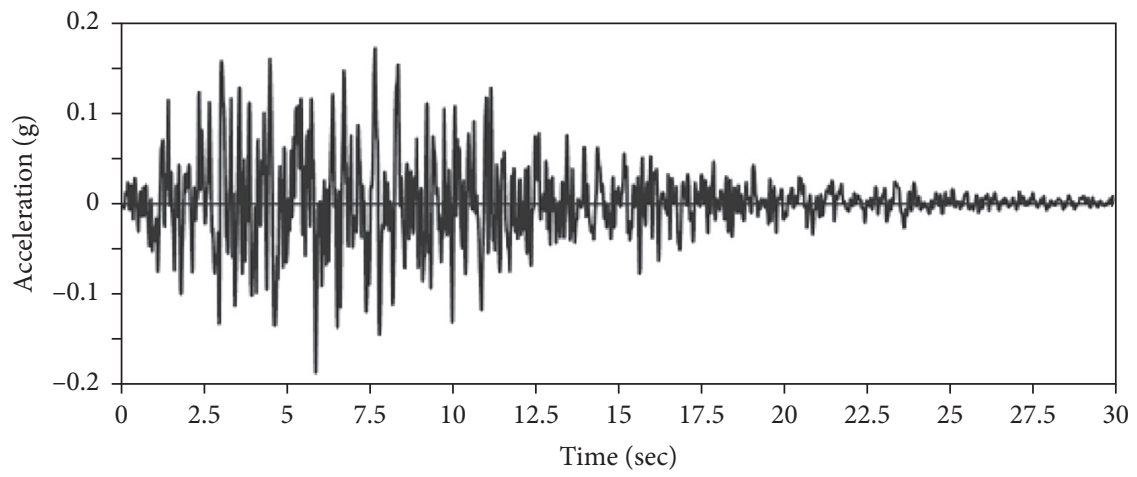

(b)

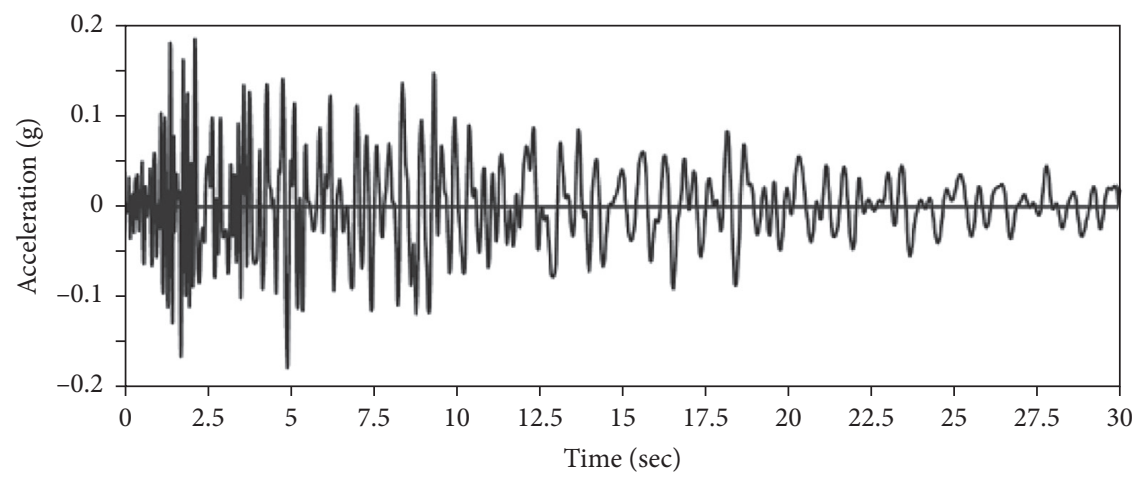

(c)

FIGURE 2: Examples of accelerograms belonging to the three sets used for this investigation: (a) stationary, (b) nonstationary evenly modulated, and (c) fully nonstationary.

structural demand and this seems to justify the choice of this type of signals for the nonlinear step-by-step analysis. Further, stationary signals have the advantage to be simple to generate and leave the structural designer free from the commitment to choose how to assign the nonstationarity, only sometimes cited but not clearly explained by the actual codes.

The fact that stationary signals are conservative in spite being consistent, as nonstationary signals, with the same target response spectrum, has to be explained with the fact that the destructive action of an earthquake cannot be identified with the peak of total acceleration experimented by a structure (this is the meaning of the pseudo acceleration response spectrum).

What emerges from the results shown in Figures 6 and 7 proves the aim of the work, evidencing the differences in the response of the same structure under different input signals. Besides, these differences are more evident in the case of building with irregular geometry. In detail, the curves obtained from the time-history analyses are sensitive to the level of regularity in plan and/or in elevation (as for the models M2, M3, and M4) and it is highlighted that 


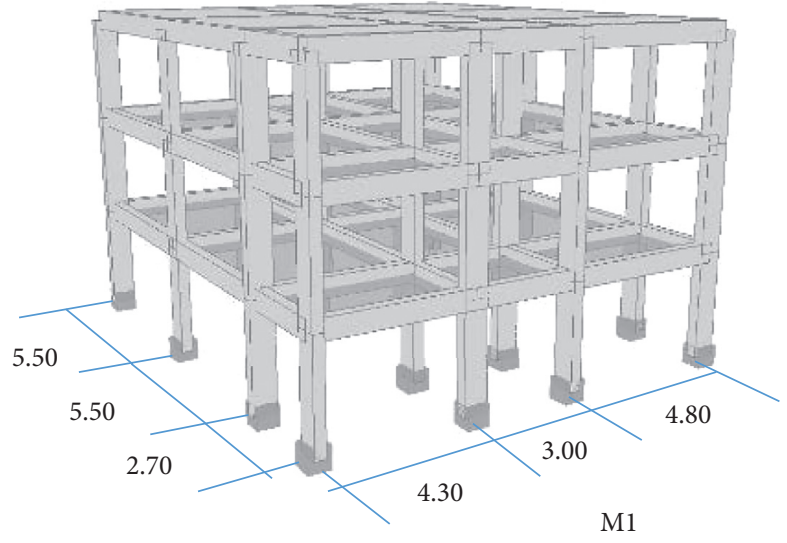

(a)

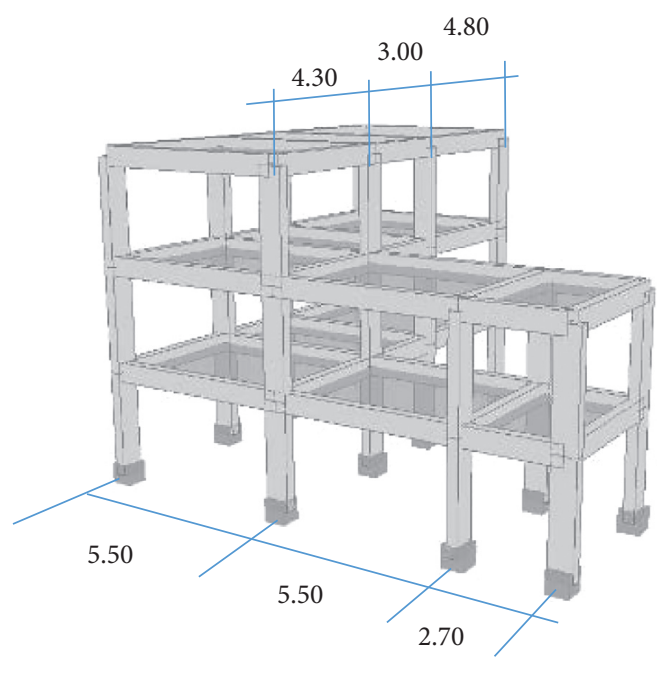

M3

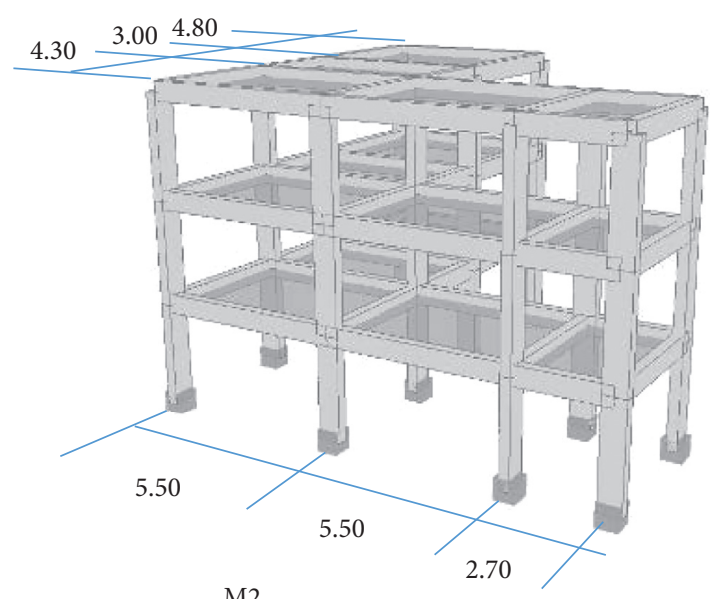

(b)

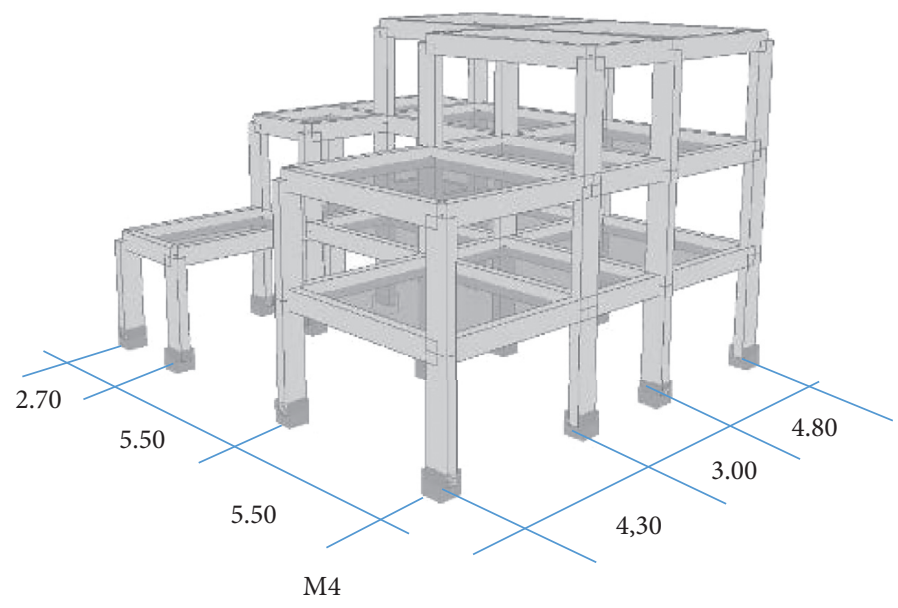

M4

(c)

(d)

Figure 3: Reference numerical models (axonometric view obtained by the software).

TABLE 2: Main design details of the reference structural models.

\begin{tabular}{lcc}
\hline & Beams & Columns \\
\hline Cross section dimension $(\mathrm{mm})$ & $300 \times 500$ & $300 \times 650$ \\
\hline Longitudinal reinforcement & $3+3 \Phi 16$ & $10 \Phi 18$ \\
\hline Shear reinforcement & $\Phi 8 / 15 \mathrm{~cm}$ & $\Phi 8 / 12 \mathrm{~cm}$ \\
\hline
\end{tabular}

the more is the nonregularity of the structure, the more the results obtained from the various inputs diverge from each other.

In more than one case, it has been proved the peak of acceleration, as expressed by the response spectrum, is not enough to describe the effects of an earthquake (an earthquake with a very high peak of acceleration may be characterized by a unique peak having very short duration associated with a very narrow impulse). Hence, in order to imagine what damage may generate an earthquake, it is basic to be able to estimate the energy carried. For this reason, starting from the accelerograms used for the above analyses and compatible with the target spectrum in Figure 1, the relative energy spectra were derived and compared as shown in Figure 8. 


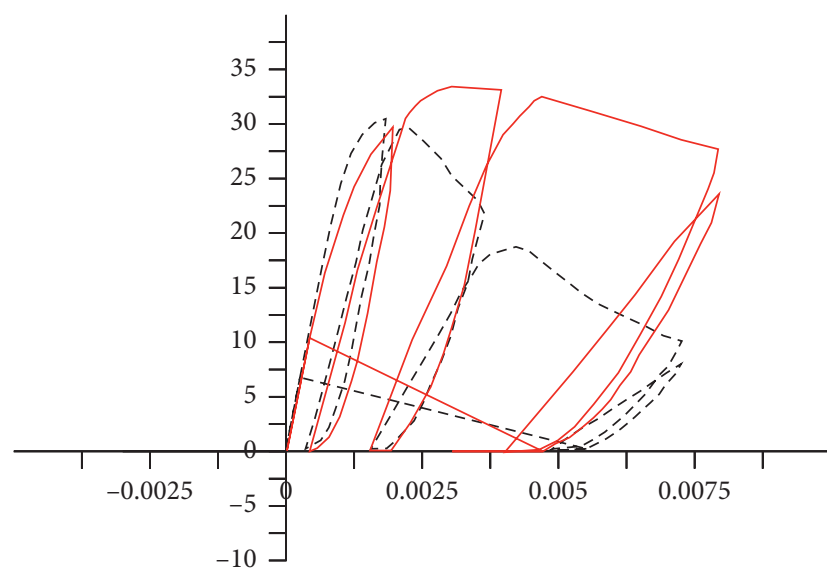

- - - Unconfined concrete

_ Confined concrete

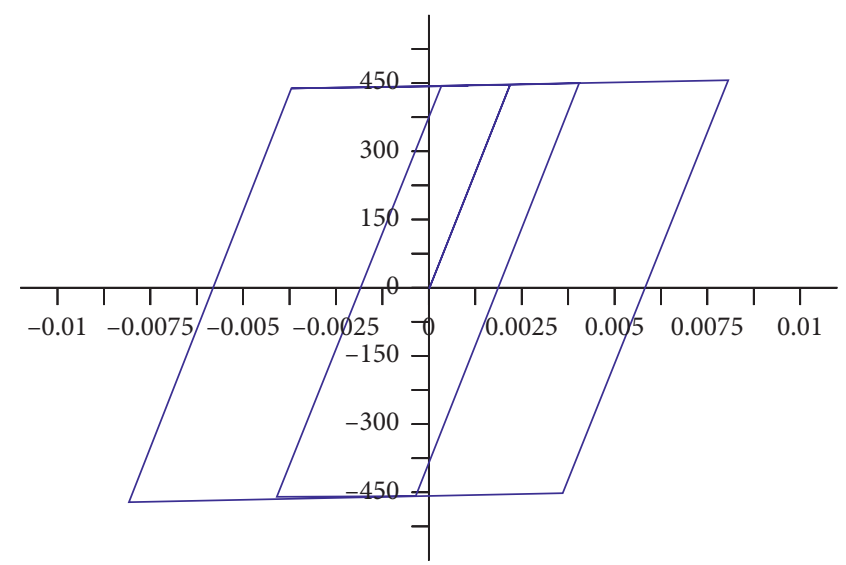

- Steel

(a)

(b)

FIGURE 4: Stress-strain laws used for the analyses. Concrete (a) and steel reinforcement (b).

The relative energy $E$ was calculated as

$$
E=\int_{0}^{t_{f}}-\ddot{u}_{i, g} \mathrm{~d} x .
$$

The comparison shows that for a fixed period $T$ the energy carried by nonstationary accelerograms is lower than that carried by the stationary accelerograms. To this point, in order to understand as the nonstationarity influences the structural response, incremental dynamic analyses were performed as below discussed.

\section{Seismic Fragility Assessment by Incremental Dynamic Analyses}

Seismic behavior obtained with nonlinear analysis observed in the previous section is closely tied to the nature of the signals adopted. Although the stationary input showed larger seismic demand with respect to the nonstationary case, the obtained results strictly depend on the target spectrum and the PGA associated with it. Therefore, Incremental Dynamic Analysis (IDA) was carried out using generated accelerograms in order to provide a wider overview and a confirmation of what concluded above.

IDA is adopted by FEMA-350 [28] and described in detail by Vamvatsikos and Cornell [29]. It is based on the definition of a relationship between an intensity measure parameter (IM) and a damage measure parameter (DM). Often, the peak ground acceleration (PGA) associated each time with a scaling level of the earthquake is assumed as IM. Sequential time-history analyses are carried out scaling the single ground motion up to collapse of the structure and the DM parameter is monitored for each scaling level.
As PGA was used as IM, the maximum interstorey drift experienced by the structure at the lowest floor was chosen as DM. Each IDA curve consisted of an average of 10 scaling points. Beyond the first collapse point (corresponding with the achieving in a structural member of an ultimate limit state condition, that is, the reaching of an ultimate strain in the concrete of the cross section cores), a subhorizontal branch followed, indicating that further increases of intensity cannot be supported by the structural system.

IDAs were conducted for M1 and M4 structural models since they present the major differences with respect to structural regularity. Furthermore, because of the high computational effort, 30 of 50 artificial ground motions of each set of artificial accelerograms were considered.

Figure 9 shows the IDA curves obtained. In such figures, the relations between PGA and maximum first-floor interstorey drift are shown.

In general, the results show a less dispersion of the collapse PGA in the case of stationary inputs. Conversely, a greater dispersion is provided by nonstationary inputs. Further, values of the collapse PGA lower than those associated with stationary inputs can be found in the case of nonstationary input. This fact seems in opposition to the result of the nonlinear analyses with a target spectrum above discussed, which mainly revealed a demand of the stationary accelerograms greater than that of the nonstationary accelerograms.

However, M4 model, as an exception, in the case of nonstationary evenly modulated accelerograms, shows dispersion in the collapse PGA slowly lower than that provided by the stationary accelerograms.

In other words, a weaker dependency on the typology of the seismic signal was recognized by IDA curves, 

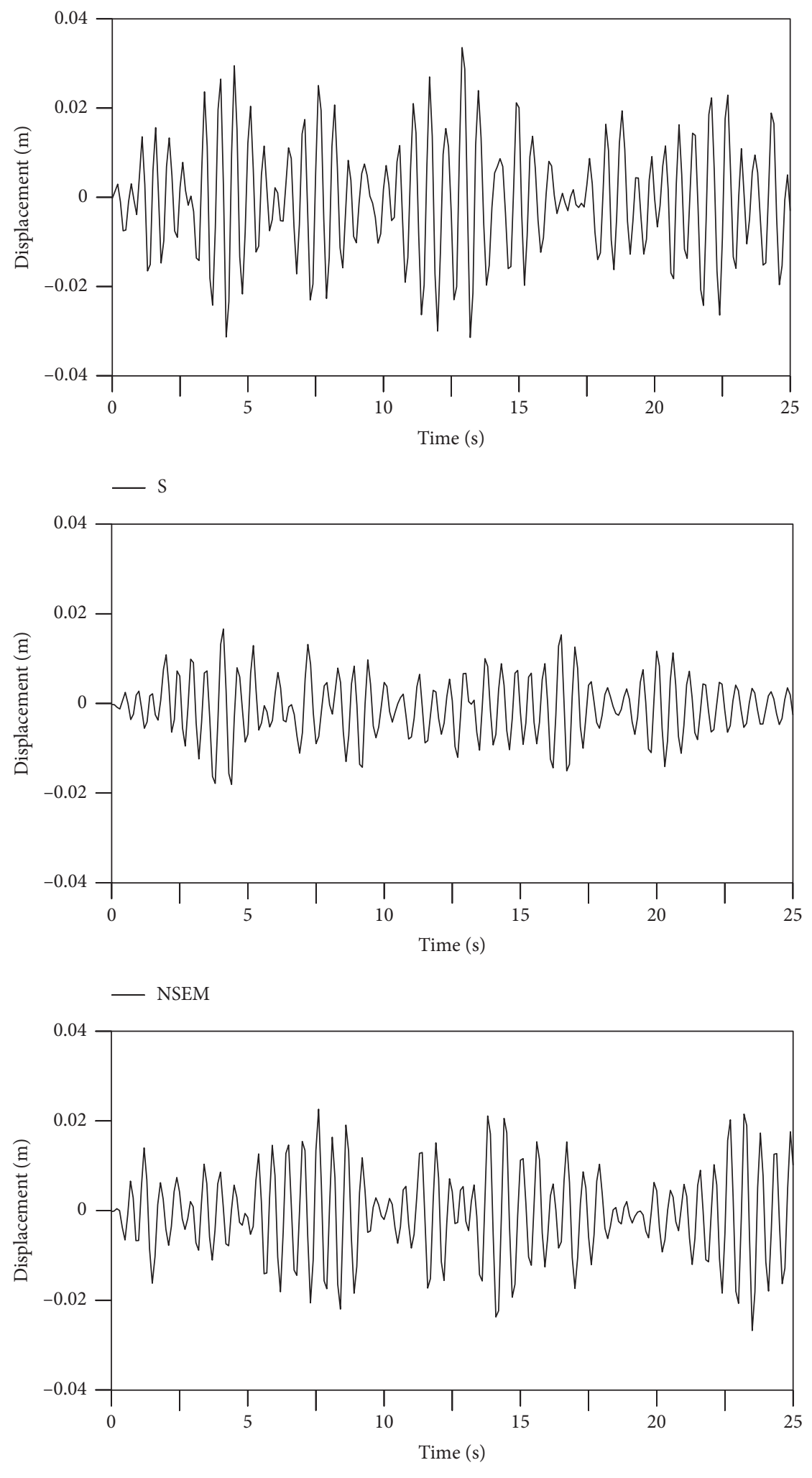

- FNS

Figure 5: Model 1 response: first-floor displacement under input samples belonging to the set of the considered artificial accelerograms. 

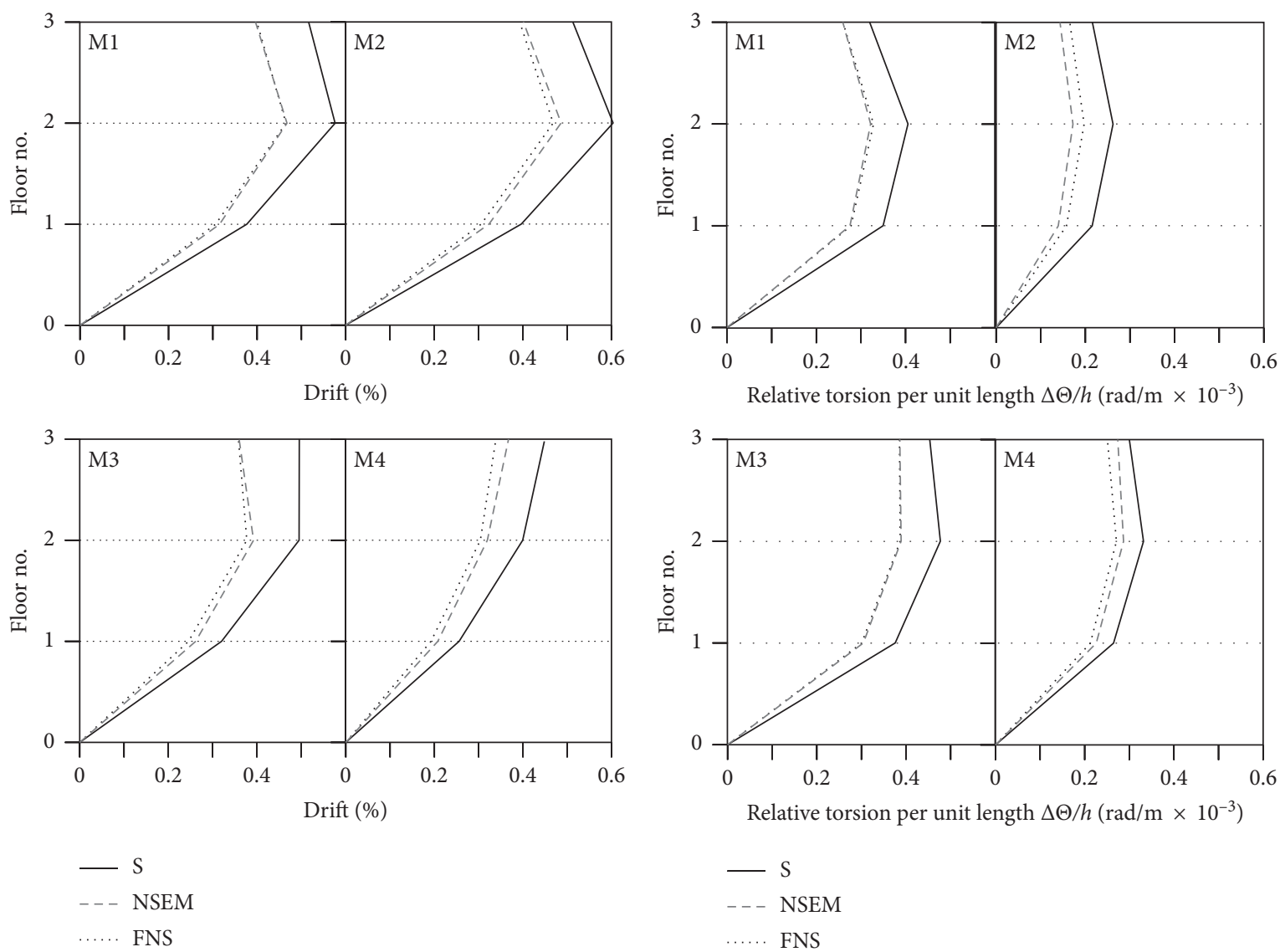

(a)

(b)

Figure 6: Average interstorey drift (a) and relative torsion per unit length (b) of M1, M2, M3, and M4 structural models obtained from three sets of the considered artificial accelerograms.

although the greater dispersion is provided by nonstationary signals.

The average IDA curves (Figure 10) reveal that the collapse in the case of nonstationary input happens for a lower value of the first-floor interstorey drift and a higher PGA than that associated with stationary accelerograms evidencing that, probably, this parameter is not the better one for the overall representation of the structural damage.

However, much more interesting conclusions can be obtained by the statistical processing of the data of the IDA curves as below discussed.

The probability density functions of the collapse PGA allow for clarifying better the influence of the type of accelerograms. In Figure 11, the aforementioned probability density functions (PDFs) are shown. These PDFs are simply derived under the hypothesis of Gaussian distribution after calculating the average and the standard deviation of the collapse PGAs for model 1 and model 4 interested by IDAs.

As regards model 1 , it is mainly confirmed that the use of stationary accelerograms is conservative but the observation of the probability values far from the averages suggests that the collapse under nonstationary inputs may precede the collapse under stationary ones. As regards model 4, on average, the nonstationary inputs produce the collapse for lower values of PGA. It means that the nonstationarity of the input, especially in the case of irregular structure, may be basic for a correct and conservative assessment of the capacity.

Further considerations may be obtained by the fragility curves. These express the probability of overcoming a specified limit state for a given seismic input motion parameter [30]. Fragility curves were derived from the IDA curves for the collapse PGA. Such curves are commonly represented using a lognormal cumulative distribution function [31,32], defining the probability of the damage exceeding the collapse limit state $\left(\mathrm{DM}_{\mathrm{CO}}\right)$ at a given $\mathrm{IM}$ as follows:

$$
P\left(\mathrm{DM} \geq \mathrm{DM}_{\mathrm{CO}}\right)=\Phi\left(\frac{\ln X-\mu_{\ln X}}{\sigma_{\ln X}}\right)
$$

where $\Phi$ is the standard cumulative distribution function, $\ln X$ is the natural logarithm of the stochastic variable $X$ (collapse PGA), and $\mu_{\ln X}$ and $\sigma_{\ln X}$ are the mean and the 

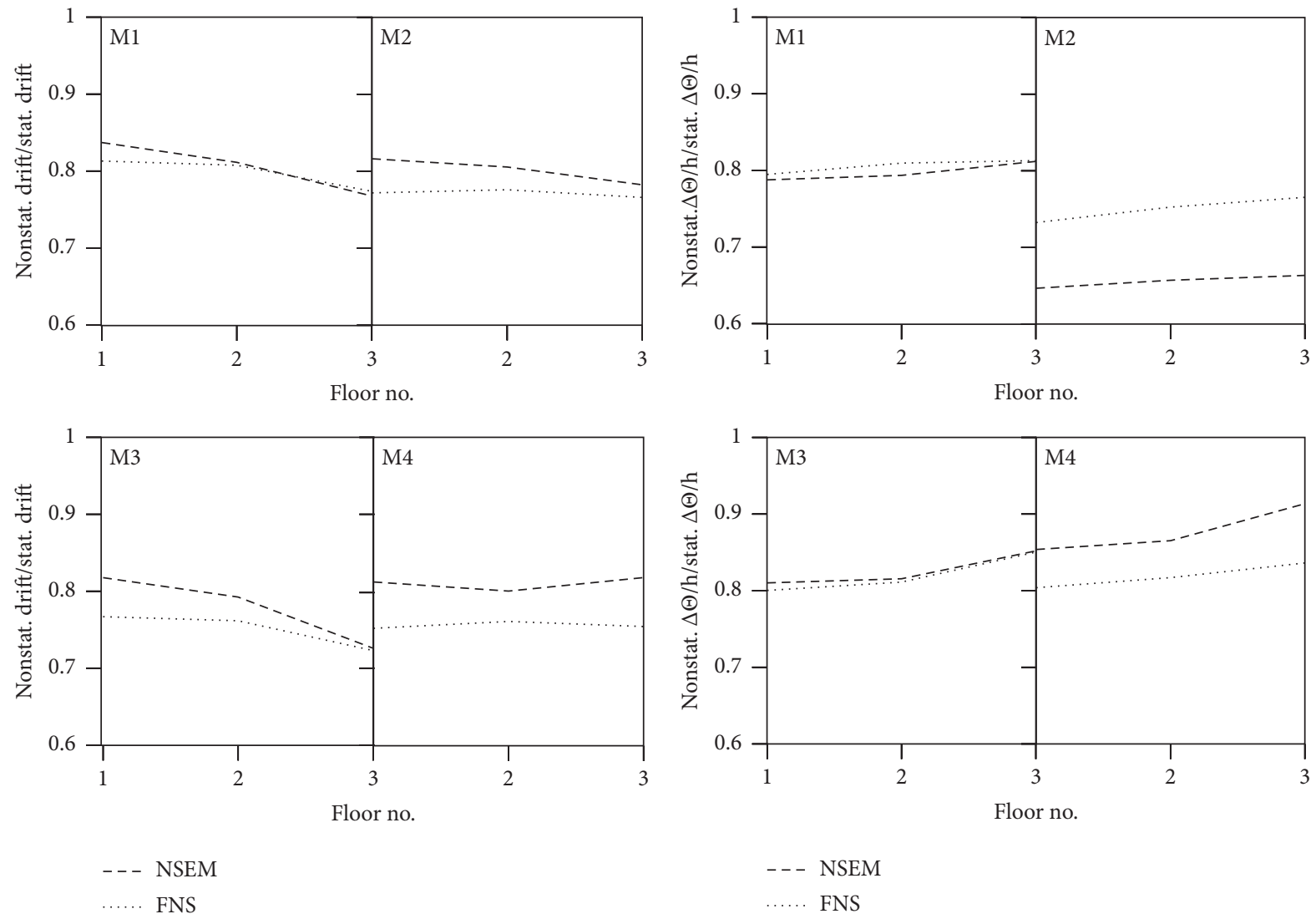

(a)

(b)

FIGURE 7: Ratios of variation of the average nonstationary interstorey drift (a) and relative torsion (b) demands with respect to the stationary ones for the considered models at the different floors.

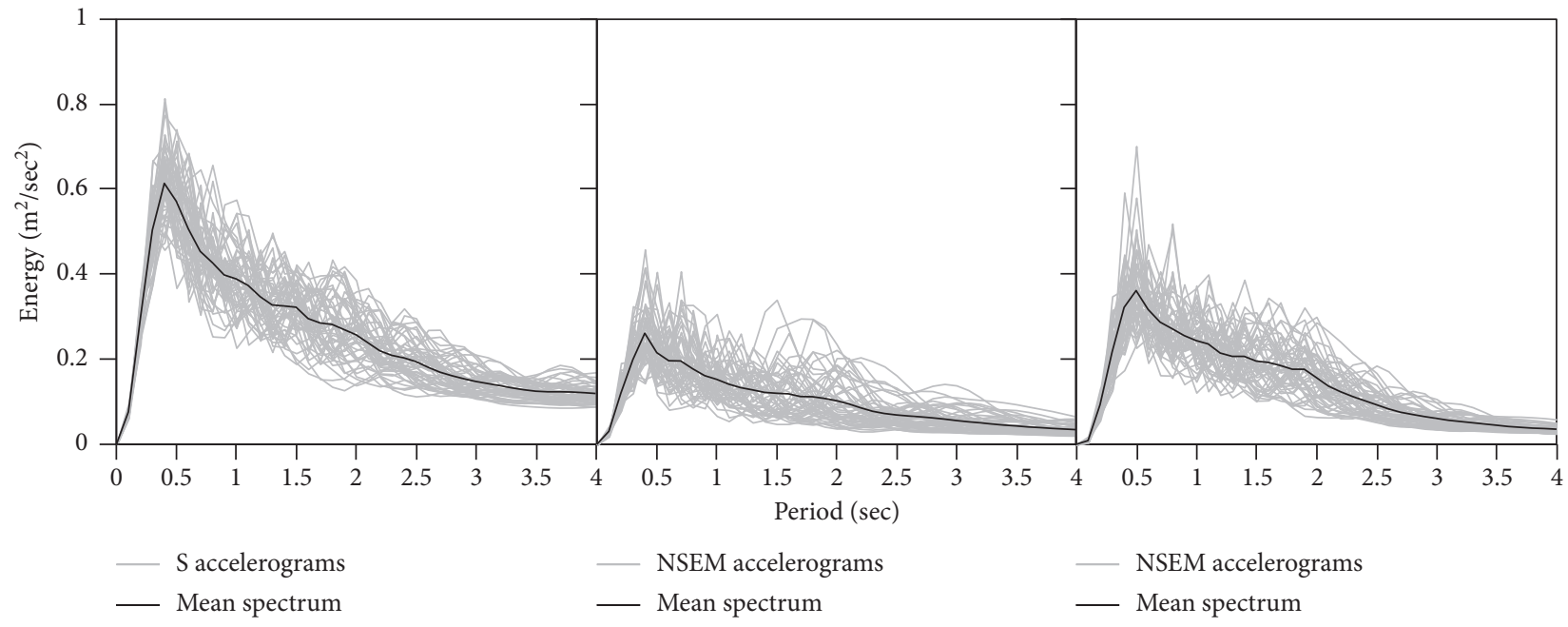

(a)

Figure 8: Continued. 


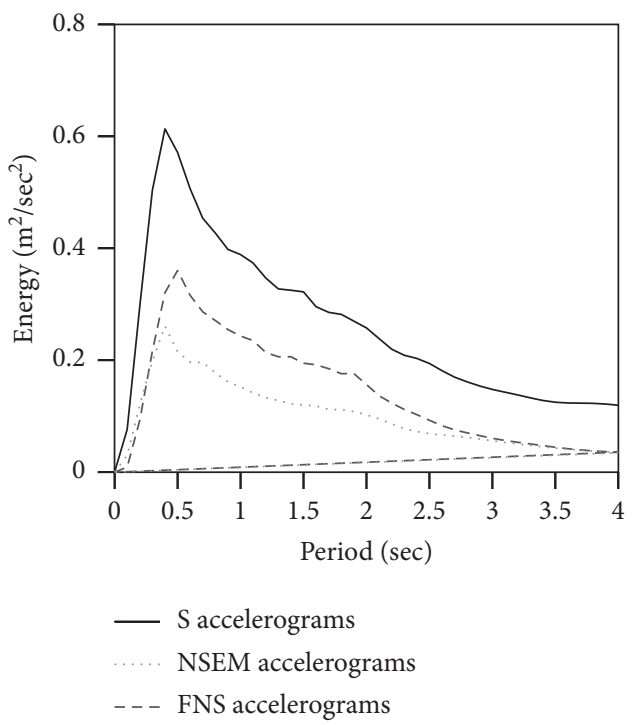

(b)

FIGURE 8: Energy spectra: (a) energy spectrum obtained from each accelerogram; (b) comparison between the mean energy spectra from each set of accelerograms.

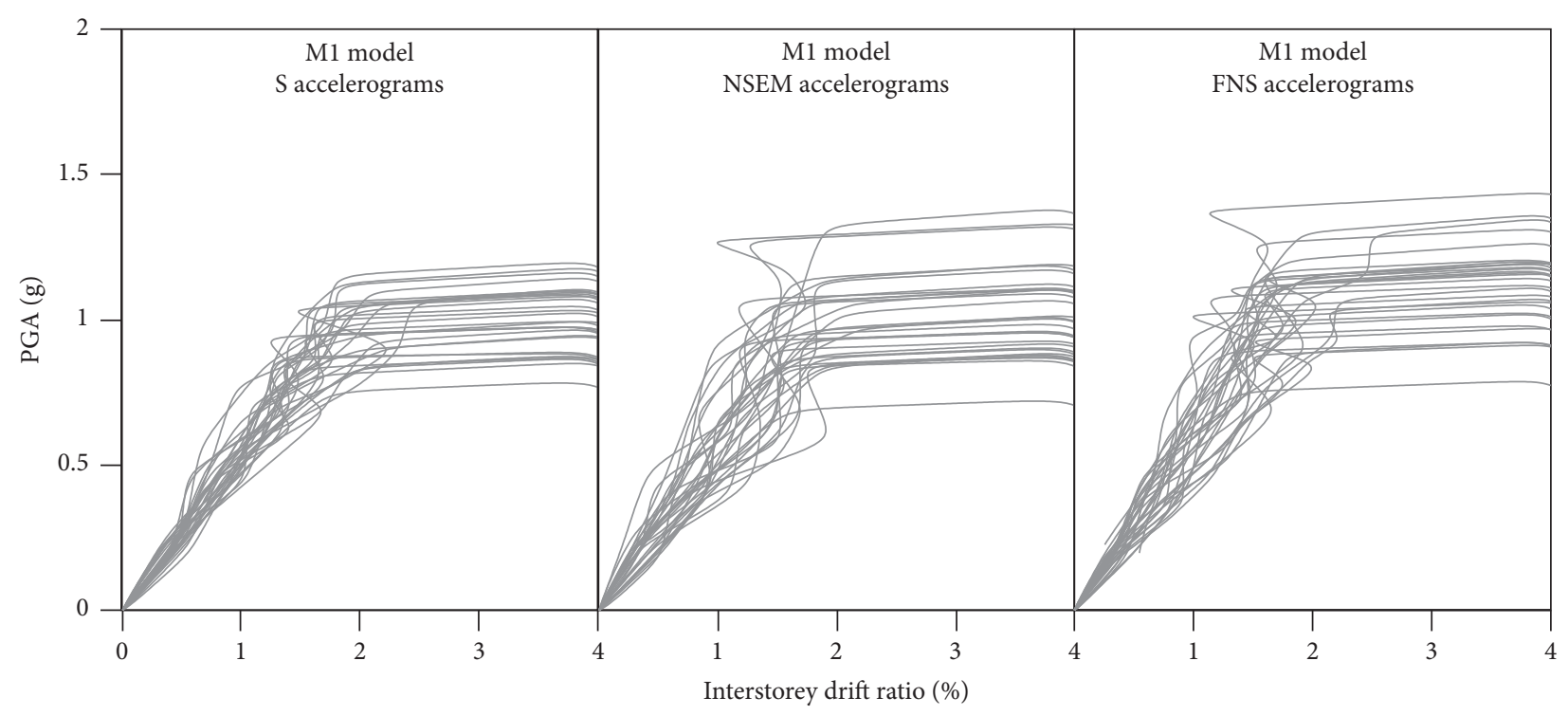

(a)

Figure 9: Continued. 


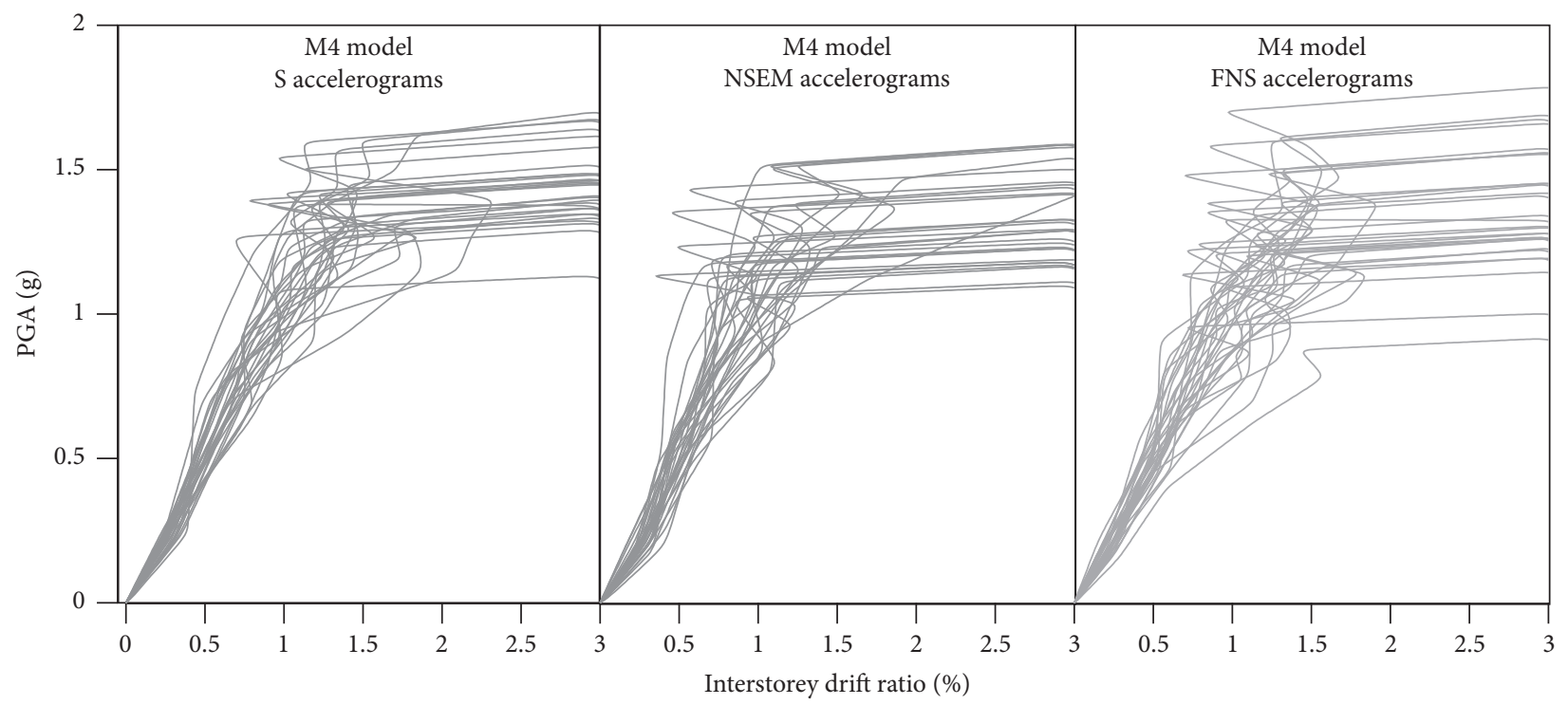

(b)

Figure 9: IDA curves (PGA vs. maximum interstorey first-floor drift ratio) for the M1 (a) and M4 (b) models for the 3 types of artificial ground motion.

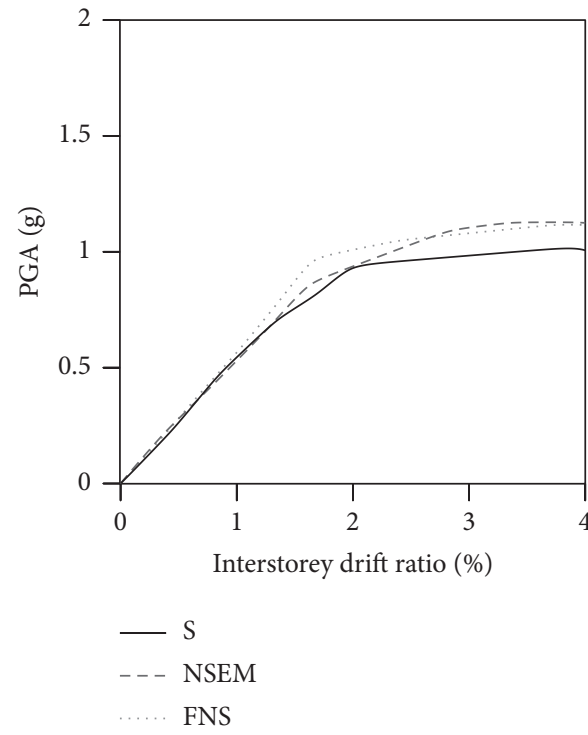

(a)

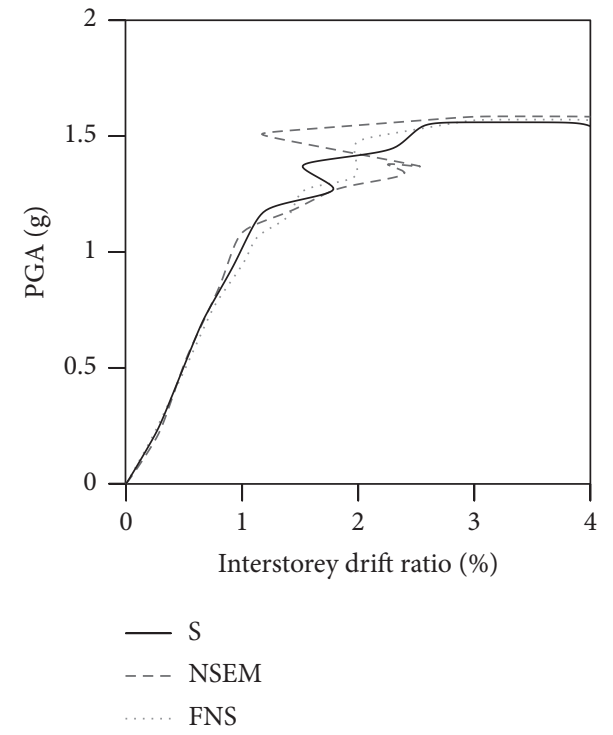

(b)

FIgURe 10: Average IDA curves (PGA vs. maximum interstorey first-floor drift ratio). (a) M1 model. (b) M4 model.

standard deviation of the natural logarithms of the distribution of $X$, respectively.

In Figure 12, analytical fragility curves for PGA are shown, evaluated for M1 and M4 model, respectively. For the regular structure M1, a reduced impact in producing seismic damaging was observed for the nonstationary case. Similar fragility curves are obtained from stationary and nonstationary evenly modulated inputs. However, various trend was observed. The probability of damage exceeding for NSEM case was larger for the lowest values of PGA. Conversely, stationary input highlighted a larger collapse probability at the highest PGA values.

For irregular structural models (Figure 12(b)), a clearly different trend was observed. The most damaging conditions were obtained from NSEM and FS inputs. 


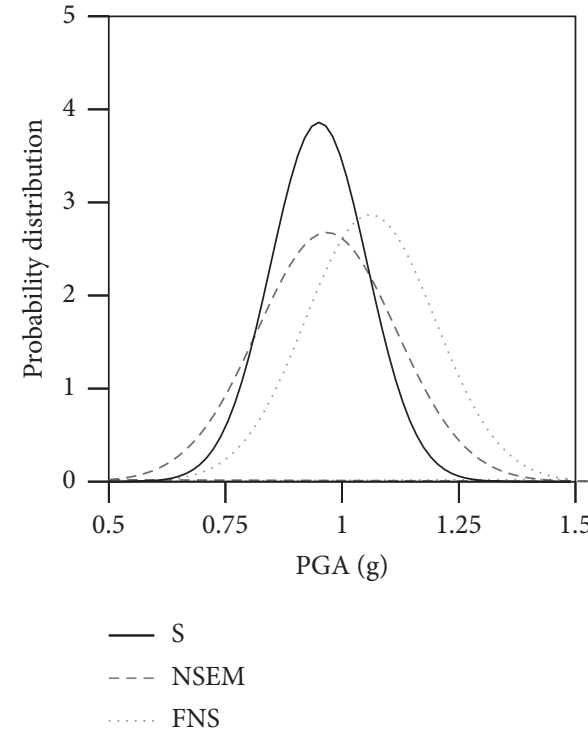

(a)

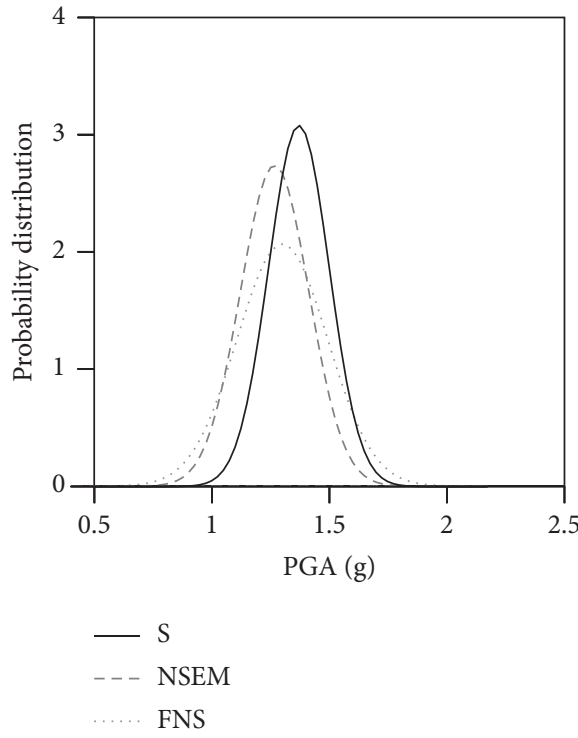

(b)

Figure 11: Probability density of the collapse PGA of M1 and M2 models. (a) M1 model collapse PGA distribution. (b) M4 model collapse PGA distribution.

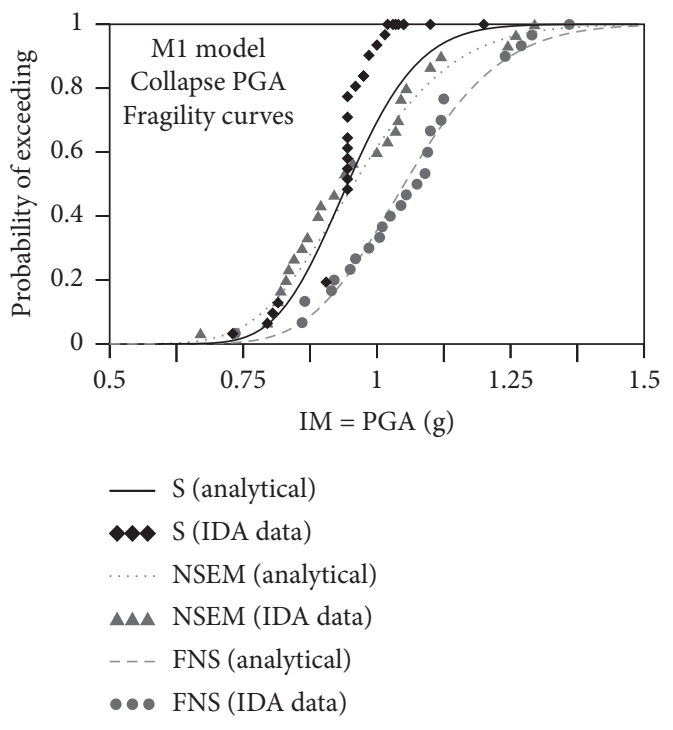

(a)

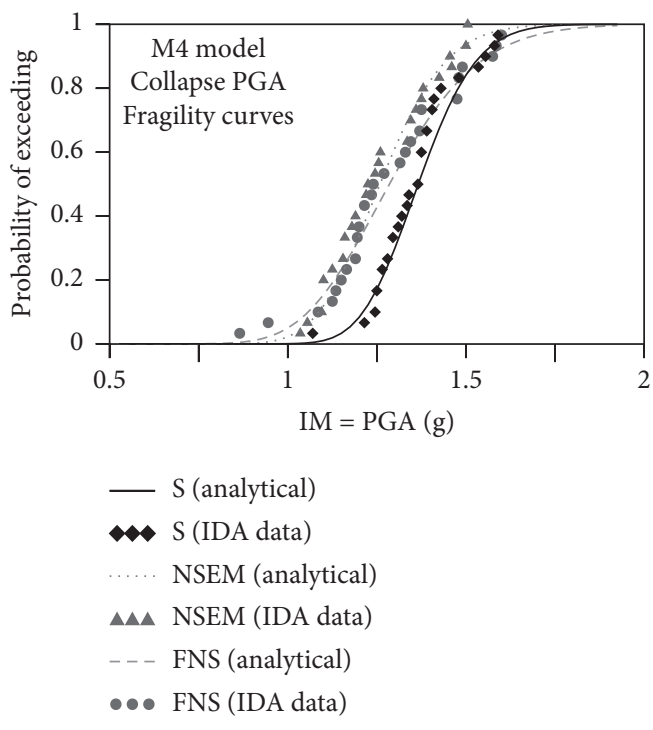

(b)

Figure 12: Fragility curves: model M1 (a) and model M4 (b): probability of collapse damage exceeding with different inputs.

\section{Conclusions}

In this paper, the effects of different typologies of spectrum compatible artificial accelerograms on the seismic response of reinforced concrete structures have been focused. Three sets of accelerograms (stationary, nonstationary evenly modulated, and fully nonstationary) have been compared. The seismic behavior of regular and irregular structural models has been evaluated using standard nonlinear time-history analyses and incremental dynamic analyses.
Nonlinear time-history analyses have highlighted that stationary accelerograms (S) produce larger seismic demand in terms of interstorey drifts and floor torsions for each structural model considered. Conversely, NSEM and FNS accelerograms provide a similar seismic demand with a reduction of $20 \%$ with respect to the stationary input case.

Fragility analysis at the collapse limit state has highlighted a different trend for the stationary and nonstationary cases. In detail, for regular structural models, fully nonstationary and nonstationary evenly modulated accelerograms provided a lower probability of collapse in the 
range of the high PGAs and a greater probability of collapse at the low PGAs with respect to the case of stationary inputs.

For irregular structural models, fragility curves have highlighted a greater sensitivity to nonstationary inputs. In particular, IDA curves obtained with nonstationary evenly modulated accelerograms and fully nonstationary accelerograms have shown the largest collapse probabilities.

The overall trend has confirmed that the seismic behavior of structures is certainly influenced by the typology of the seismic input. The fragility analysis has revealed being sensitive to the nature of the seismic record and able to recognize the highest collapse probability of irregular structural models under nonstationary input.

\section{Data Availability}

The data used to support the findings of this study are available from the corresponding author (liborio.cavaleri@ unipa.it) upon request.

\section{Conflicts of Interest}

The authors declare that there are no conflicts of interest.

\section{Authors' Contributions}

All authors have participated in (a) conception and design or analysis and interpretation of the data; (b) drafting the article or revising it critically for important intellectual content; and (c) approval of the final version.

\section{References}

[1] CEN, Eurocode 8: Design of Structures for Earthquake Resistance-Part 1: General Rules, Seismic Actions and Rules for Buildings, European Commitee for Standardization, Brussels, Belgium, 2004.

[2] M. E. Arslan and A. Durmus, "Construction stage effect on the dynamic characteristics of RC frame using operational modal analysis," Computers and Concrete, vol. 12, no. 1, pp. 79-90, 2013.

[3] S. G. Joshi, S. N. Londhe, and N. Kwatra, "Application of artificial neural networks for dynamic analysis of building frames," Computers and Concrete, vol. 13, no. 6, pp. 765-780, 2014.

[4] O. Merter, T. Ucar, and M. Duzgun, "Determination of earthquake safety of RC frame structures using an energybased approach," Computers and Concrete, vol. 19, no. 6, pp. 689-699, 2017.

[5] X. Wu, Y. Li, and Y. Zhang, "Elasto-plastic time history analysis of a 117-story high structure," Computers and Concrete, vol. 19, no. 1, pp. 7-17, 2017.

[6] X. Wu, Y. Sun, M. Rui, M. Yan, L. Li, and D. Liu, "Elastoplastic time history analysis of an asymmetrical twin-tower rigid-connected structure," Computers and Concrete, vol. 12, no. 2, pp. 221-280, 2013.

[7] G. Falsone and F. Neri, "Stochastic modelling of earthquake excitation following the EC8: power spectrum and filtering equations," European Earthquake Engineering, vol. 14, no. 1, pp. 3-12, 2000.
[8] A. Preumont, "A method for the generation of artificial earthquake accelerograms," Nuclear Engineering and Design, vol. 59, no. 2, pp. 357-368, 1980.

[9] C. Sundararajan, "An iterative method for the generation of seismic power spectral density functions," Nuclear Engineering and Design, vol. 61, no. 1, pp. 13-23, 1980.

[10] M. Barbato and J. P. Conte, "Spectral characteristics of nonstationary random processes: theory and applications to linear structural models," Probabilistic Engineering Mechanics, vol. 23, no. 4, pp. 416-425, 2008.

[11] I. Iervolino, G. Manfredi, and E. Cosenza, "Ground motion duration effects on nonlinear seismic response," Earthquake Engineering \& Structural Dynamics, vol. 35, no. 1, pp. 21-38, 2006.

[12] P. D. Spanos and W. Y. Tein, "Spectral estimation of bivariate non-stationary processes," in Proceedings of the Tenth World Conference on Earthquake Engineering, Balkema, Madrid, Spain, July 1992.

[13] P. Cacciola, "A stochastic approach for generating spectrum compatible fully nonstationary earthquakes," Computers \& Structures, vol. 88, no. 15-16, pp. 889-901, 2010.

[14] G. G. Amiri, A. Bagheri, and M. Fadavi, "New method for generation of artificial ground motion by a nonstationary Kanai-Tajimi model and wavelet transform," Structural Engineering and Mechanics, vol. 26, no. 6, pp. 709-723, 2007.

[15] F. R. Refooei, A. Mobarake, and G. Ahmadi, "Generation of artificial earthquake records with a nonstationary KanaiTajimi model," Engineering Structures, vol. 23, no. 7, pp. 827-837, 2001.

[16] G. Alotta, L. Cavaleri, M. Di Paola, and M. F. Ferrotto, "Solutions for the design and increasing of efficiency of viscous dampers," The Open Construction and Building Technology Journal, vol. 10, no. 1, pp. 106-121, 2016.

[17] N. S. Armouti, "Response of structures to synthetic earthquakes," 9th Arab Structural Engineering Conference, vol. 1, pp. 331-340, 2003.

[18] P. G. Asteris, L. Cavaleri, F. Di Trapani, G. Macaluso, and G. Scaduto, "Definition of seismic vulnerability maps for civil protection systems: the case of Lampedusa Island," The Open Construction and Building Technology Journal, vol. 10, no. 1, pp. 87-105, 2016.

[19] L. Cavaleri, F. Di Trapani, and P. G. Asteris, "Seismic analysis and risk mitigation of existing constructions," The Open Construction and Building Technology Journal, vol. 10, no. 1, pp. 39-41, 2016.

[20] L. Cavaleri, F. Di Trapani, and M. F. Ferrotto, "A new hybrid procedure for the definition of seismic vulnerability in mediterranean cross-border urban areas," Natural Hazards, vol. 86, no. S2, pp. 517-541, 2017.

[21] M. Shinozuka and Y. Sato, "Simulation of nonstationary random process," Journal of Engineering Mechanics ASCE, vol. 93, no. 1, pp. 11-40, 1967.

[22] T.-I. Hsu and M. C. Bernard, "A random process for earthquake simulation," Earthquake Engineering \& Structural Dynamics, vol. 6, no. 4, pp. 347-362.

[23] P. T. D. Spanos and G. P. Solomos, "Markov approximation to transient vibration," Journal of Engineering Mechanics, vol. 109, no. 4, pp. 1134-1150, 1983.

[24] Italian Building Code 2008, CS.LL.PP. DM 14 Gennaio, Norme Tecniche per le Costruzioni, Gazzetta Ufficiale della Repubblica Italiana, Rome, Italy, 2008.

[25] SeismoSoft, A Computer Program for Static and Dynamic Nonlinear Analysis of Frames Structures, SeismoSoft, Pavia, Italy, 2013. 
[26] G. Campione, L. Cavaleri, M. F. Ferrotto, G. Macaluso, and M. Papia, "Efficiency of stress-strain models of confined concrete with and without steel jacketing to reproduce experimental results," The Open Construction and Building Technology Journal, vol. 10, no. 1, pp. 65-86, 2016.

[27] J. B. Mander, M. J. N. Priestley, and R. Park, "Theoretical stress-strain model for confined concrete," Journal of Structural Engineering, vol. 114, no. 8, pp. 1804-1826, 1988.

[28] FEMA-350, Recommended Seismic Design Criteria for New Steel Moment Frame Buildings, Federal Emergency Management Agency, Washington, DC, USA, 2000.

[29] D. Vamvatsikos and C. A. Cornell, "Incremental dynamic analysis," Earthquake Engineering \& Structural Dynamics, vol. 31, no. 3, pp. 491-514, 2002.

[30] T. Rossetto and A. Elnashai, "Derivation of vulnerability functions for European-type RC structures based on observational data," Engineering Structures, vol. 25, no. 10, pp. 1241-1263, 2003.

[31] P. Castaldo, B. Palazzo, and T. Ferrentino, "Seismic reliabilitybased ductility demand evaluation for inelastic base-isolated structures with friction pendulum devices," Earthquake Engineering \& Structural Dynamics, vol. 46, no. 8, pp. 1245-1266, 2016.

[32] E. Tubaldi, L. Ragni, and A. Dall'Asta, "Probabilistic seismic response assessment of linear systems equipped with nonlinear viscous dampers," Earthquake Engineering \& Structural Dynamics, vol. 44, no. 1, pp. 101-120, 2014. 